\title{
|PESQUISA ETNOGRÁFICA: EVOLUÇÃO E CONTRIBUIÇÃO PARA A ENFERMAGEM
}

\author{
Ethnographical Research: Evolution and \\ Contribution to the Nursing \\ Investigación Etnográfica: Evolución y \\ Contribución para la Enfermería
}

Leilane Barbosa de Sousa ${ }^{1}$

Maria Grasiela Teixeira Barroso ${ }^{2}$

\section{Resumo}

Diante da expressão que a etnografia adquiriu na pesquisa em Enfermagem, realizamos este estudo com o objetivo de promover reflexão sobre a evolução da etnografia e suas possibilidades de aplicação no contexto atual. 0 trabalho apresenta a análise reflexiva da etnografia desenvolvida nas tribos e as considerações sobre sua aplicação em ambiente urbano, inclusive abordando a pesquisa sobre o fenômeno do cuidado transcultural de Enfermagem. Esperamos que 0 artigo contribua para a reflexão sobre a impor tância da abordagem etnográfica e incentive sua utilização adequada na Enfermagem.

Palavras-chave: Cultura. Pesquisa. Enfermagem.

\begin{abstract}
In face of the expression that the ethnography has acquired with the researching in nursing care, this study has been accomplished with the objective of fomenting the reflection about the evolution of the ethnography and its possibilities of being applied in the current context. This study shows us one reflexive analysis of the ethnography developed in aboriginal tribes and the relevance about its application in urban environment, approaching even the research in the phenomena of the transcultural nursing care. We hope this article could contribute for the reflection on the importance of the ethnographical approach and also it could encourage its adequate using in nursing care.
\end{abstract}

\section{Resumen}

Delante la expresión que la etnografía obtuvo en la encuesta de Enfermería, realizamos este estudio, con la intención de suscitar reflexión sobre la evolución de la etnografía y sus posibilidades de aplicación en el contexto actual. El trabajo presenta el análisis reflexiva de la etnografía desarrollada en las tribus y las consideraciones sobre su aplicación en ambiente urbano, incluso se aborda en la pesquisa sobre el fenómeno del cuidado transcultural de Enfermería. Esperamos que el artículo contribuya con la reflexión sobre la importancia de la abordaje etnográfico e impulse su utilización adecuada en la Enfermería. 


\section{INTRODUÇÃO}

A etnografia, entendida como modalidade de pesquisa científica primordialmente de caráter qualitativo, possui traços da fenomenologia, do interacionismo simbólico e da sociologia. Ainda não há um consenso a respeito de sua representação, que por vezes é entendida como uma área especial dentro da sociologia, uma metodologia e uma escola. Provavelmente a etnografia constitui um pouco de cada um destes elementos, inserindo-se certamente na tradição do interacionismo simbólico, por meio da qual se busca compreender o mundo pelo olhar dos próprios atores sociais. A priori, esta compreensão tem como fim o fornecimento de subsídios para diversas áreas do conhecimento, no intuito de melhorar as condições de vida e promover o desenvolvimento do ser humano.

A pesquisa etnográfica fundamenta-se na inserção do pesquisador em um campo diferente, do ponto de vista cultural, de seu próprio habitat durante um longo período. A prática etnográfica consiste basicamente em estabelecer relações, selecionar informantes e tentar salvar o dito em um discurso social em formas pesquisáveis².

0 estudo de caráter etnográfico é realizado segundo dois conjuntos de hipóteses sobre o comportamento do homem: a hipótese naturalista-ecológica e a hipótese qualitativo-fenomenológica ${ }^{3}$.

Segundo os pressupostos da hipótese naturalista-ecológica, o homem se comporta de acordo com o ambiente em que vive. Neste sentido, a sociedade, a comunidade, a família e até mesmo elementos materiais e simbólicos exercem influência sobre pensamento, atitude e comportamento humanos. A hipótese qualitativo-fenomenológica, por sua vez, afirma que, para entender o comportamento humano, é necessário considerar as relações que influenciam a interpretação, os pensamentos, os sentimentos e as ações.

As duas hipóteses trazem como ponto-chave da etnografia o estudo sobre o comportamento humano realizado a partir do contexto do indivíduo, a fim de abstrair o significado de símbolos e compreender como as pessoas os interpretam e direcionam suas atitudes. De fato, desde o nascimento, o homem, único ser "culturado", é envolvido pelos hábitos e costumes de sua comunidade e comporta-se de acordo com os ensinamentos recebidos e com as atitudes aceitas por seu contexto sócio-cultural ${ }^{4}$. A etnografia surge como caminho para se estudar o homem em sua cultura.

A etnografia utiliza um método de pesquisa diferente dos tradicionais. Nestes, os problemas sociais geralmente são vistos e tratados de forma superficial, por meio da admissão da existência de objetos independentes de crenças e das opiniões de diferentes sujeitos. 0 método etnográfico parte do pressuposto de que é improvável que a realidade seja totalmente apreendida; entretanto, tem como princípio a busca exaustiva do conhecimento por meio da interação entre o discurso e o comportamento das pessoas, e as observações do pesquisador sobre cada detalhe que compõe os ambientes físico e social pesquisados. 0 estudo etnográfico possibilita ao pesquisador adentrar no contexto sóciocultural de seus informantes e conhecer seus valores, comportamentos, crenças e visões de mundo ${ }^{5}$.

Na realização de uma pesquisa etnográfica, o pesquisador deve estar preparado para um trabalho que, apesar de parecer simples, requer certas habilidades e sensibilidades. Ao inserirse no campo, o etnógrafo deve observar e descrever minuciosamente tudo que capta por meio de todos os seus sentidos. 0 sucesso deste tipo de investigação depende muito da conduta do pesquisador. Uma vez que a observação, a descrição e a análise constituem a essência da compreensão do estudo, o pesquisador deve possuir algumas qualidades importantes, como: ser tolerante a ambigüidades, ser sensível, ser empático e possuir habilidade na expressão escrita ${ }^{6}$.

A descrição rica e detalhada do comportamento humano, presente em trabalhos de caráter etnográfico, é bastante significativa como guia para a elaboração de intervenções de enfermagem, sobretudo em situações em que o cliente interfere de forma direta no cuidado por meio de crenças e valores cultivados em seu ambiente cultural.

Entendendo que a etnografia constitui um método importante para a Enfermagem, sobretudo porque sua aplicação pode subsidiar novas e eficientes formas de elaborar o cuidado, nos propomos aqui a promover reflexão sobre a evolução da etnografia e suas possibilidades de aplicação no contexto atual, inclusive para a Enfermagem, em investigações sobre 0 fenômeno do cuidado cultural.

\section{PESQUISA ETNOGRÁFICA: DA ORIGEM AOS NOSSOS DIAS}

A pesquisa etnográfica é um método antigo que vem atravessando séculos e sendo aplicado nas mais diversas áreas do conhecimento. Inicialmente, possuía caráter histórico, restringindo-se à investigação da cultura de civilizações exóticas por meio da análise dos instrumentos que elas produziam, os quais eram obtidos por viajantes e analisados pelos até então denominados etnógrafos. A investigação cultural, no início, considerava apenas os objetos manufaturados, desvalorizando a relação interpessoal, o pensamento e o comportamento humano. Gradativamente a etnografia ganhou outros espaços, tornando-se presente desde a investigação da cultura de outros países para fins jornalísticos ao estudo do comportamento humano para aplicação na área da saúde.

Até chegar ao cenário urbano, a etnografia passou por três períodos críticos conhecidos como as revoluções da etnografia?. Alguns pesquisadores ainda consideram o método etnográfico de difícil aplicação e inadequado o uso do termo pesquisa etnográfica para estudos realizados em ambiente urbano, com pessoas comuns, que falam nosso idioma, e em lugares públicos. Nossa proposta é abordar a transição da etnografia das tribos para a etnografia das cidades e nas cidades e, a partir daí, suscitar reflexões a respeito de sua aplicação nos nossos dias.

Por volta do século XIX iniciava-se a realização do até então chamado trabalho etnográfico, ainda sem características antropológicas. A pesquisa acontecia à distância. Não havia contato entre pesquisador e campo, nem tão pouco entre pesquisador e informantes. 0 chamado etnógrafo pesquisava civilizações distantes e exóticas, pessoas por ele consideradas "estranhas", como índios. Para a obtenção de dados, o etnógrafo enviava questionários a viajantes e missionários e pedia-lhes que trouxessem todos os artefatos que fosse possível, tais como, 
flechas, objetos de barro, lanças e vestimentas. Importante salientar que estes viajantes, na maioria das vezes, tinham seus objetivos particulares nas viagens, não viajavam com 0 intuito de pesquisar a cultura das sociedades.

Entre 1915 e 1920 aconteceu a primeira revolução da etnografia, quando Bronislau Malinowski resolveu realizar pessoalmente sua pesquisa. Defendendo a idéia de que o pesquisador deveria ir ao campo de estudo para procurar os dados que lhe interessam, introduziu o trabalho de campo ao estudo etnográfico. Malinowski realizou um estudo com indígenas no intuito de captar suas visões de mundo, não os considerando animais exóticos, mas pessoas que necessitavam de empatia e respeito. Desde então o trabalho etnográfico de campo passou a ser considerado o princípio e o fim da antropologia social ${ }^{8}$.

As pesquisas, até então restritas a tribos indígenas e civilizações "estranhas", começaram a ser repensadas. Iniciavase a segunda revolução, entre 1930 e 1935. Após ter estudado tribos aborígines na Austrália, Lloyd Warner iniciou estudos em pequenas cidades, tratando-as como microssociedades. A pesquisa urbana dava seus primeiros passos sob subsídio do Departamento de Sociologia da Universidade de Chicago. Robert Park, um dos fundadores deste departamento, iniciava seus alunos na cidade de Chicago no estudo de campo. 0 Departamento de Sociologia da Universidade de Chicago baseava seus estudos no princípio de que a etnografia não se fazia somente em tribos indígenas, pois a cidade é um laboratório natural. Posteriormente, esse departamento veio a se tornar a "Escola de Chicago".

A terceira revolução, por volta de 1950, foi caracterizada pelo desprendimento da tendência da realização de estudos etnográficos apenas com classes tidas como marginalizadas pela sociedade, como pobres, desajustados, deficientes físicos, dentre outros.

A etnografia passou a ser uma pesquisa passível de ser realizada em qualquer lugar, com quaisquer tipos de pessoas, desde que 0 método fosse sistematizado e realizado de forma adequada. Convém afirmar que o método não é propriedade de uma minoria. É sabido que o trabalho etnográfico não é simples, mas também não exige que o pesquisador possua anos de formação. Por meio do estudo de outras pesquisas, da investigação detalhada sobre experiências de campo e da supervisão de um pesquisador experiente, é possível iniciar uma pesquisa etnográfica e aprender com os próprios erros e acertos ${ }^{7}$.

Após discutirmos sobre a evolução da etnografia e as diversas possibilidades de sua realização, resta-nos uma indagação: como realizar um trabalho verdadeiramente etnográfico nos nossos dias? Realizar uma pesquisa etnográfica consiste, em suma, em observar, estabelecer relações, selecionar informantes, manter um diário, dentre outras atividades. Entretanto, não é a realização destas técnicas que define uma pesquisa como etnográfica². Como afirmamos anteriormente, a pesquisa etnográfica não é um tipo de pesquisa fácil de ser executada. Para a caracterização de um trabalho etnográfico, são apontadas muitas exigências que devem ser utilizadas como base para a operacionalização da pesquisa.

A escolha da abordagem etnográfica deve ser cuidadosamente analisada. Alguns critérios são apontados para orientar a escolha da etnografia e a classificação de um estudo como etnográfico. Entre eles, deve-se analisar se: o problema é redescoberto no campo, o pesquisador realiza a maior parte do trabalho pessoalmente, o trabalho é realizado em um período significativo para o estudo, o pesquisador teve experiências com outras culturas, houve combinação de vários métodos e se o relatório apresenta uma grande quantidade de dados primários (produzidos pelos próprios informantes) 3 .

0 trabalho etnográfico consiste em um estudo profundo e exaustivo sobre o contexto e o comportamento de pessoas. Para captar da forma mais fidedigna esta teia de relações a apresentá-la de forma eficiente em uma pesquisa, é necessário que o pesquisador possua também algumas habilidades. Fundamentada em uma observação sistematizada, a etnografia exige que o pesquisador saiba ver realmente tudo que está à sua volta. Ver, no sentido etnográfico, vai além da visão propriamente dita, alcança o âmbito de perceber o ambiente e as interações com todos os sentidos e apreendê-lo nas diversas dimensões possíveis. 0 fazer a etnografia é comparado à leitura de um manuscrito estranho, ou mais especificamente à construção da leitura deste manuscrito ${ }^{2}$.

A outra exigência para o etnógrafo é saber estar com as pessoas do campo e consigo mesmo. É preciso que o pesquisador se desarme de seus pré-conceitos e desenvolva um novo olhar sobre os informantes, não assumindo um conhecimento prévio sobre o que está certo ou errado na cultura destes ${ }^{9}$. Embora pareça simples, observar, no método etnográfico, requer uma habilidade peculiar, onde saber portar-se diante dos demais é extremamente relevante para a obtenção de dados. É necessário que o pesquisador não seja visto como um intruso pelas pessoas, muito menos que ele se esconda delas. 0 verdadeiro etnógrafo permanece no campo como pesquisador e mesmo assim deixa de ser visto como um intruso. Entretanto, essa passagem de intruso para amigo não acontece de forma rápida, requer tempo e sensibilidade, além de um verdadeiro interesse nos informantes e em suas crenças e valores ${ }^{9}$.

0 observado e as interações em campo precisam, por sua vez, ser devidamente apresentados aos leitores, do contrário o trabalho etnográfico perde o sentido de informar para melhorar condições humanas e, na melhor das hipóteses, servirá apenas para a evolução do próprio pesquisador. Para retratar comportamentos e modos de vida, o trabalho etnográfico exige que o pesquisador saiba escrever. Esta escrita deve ser criteriosamente planejada para que o leitor tenha uma visão fidedigna da realidade. Para isso, os textos etnográficos não podem ser tão rústicos, por tratar-se de documentos dirigidos, sobretudo, para a classe científica; mas também não podem ser superficiais nem muito formais, pois há o risco de perderem a essência e serem desacreditados. A construção de representações impecáveis, sem características informais, contribui para o descrédito da análise cultural².

Preenchidas as exigências, o pesquisador pode partir para a escolha do campo de pesquisa. As diversidades culturais nos deixam à disposição campos riquíssimos nas cidades ou em sociedades fechadas. Entretanto, alguns campos são tidos como mais adequados para a realização desse tipo de pesquisa. Uma vez que a validação de um estudo etnográfico reside 
fundamentalmente na sistematização do estudo, algumas considerações são feitas a respeito de campos adequados para a realização de pesquisas etnográficas. Lugares públicos ou semipúblicos são preferíveis a campos privados; o campo deve ser confor tável do ponto de vista ambiental e de segurança; e os lugares devem ser simples e de fácil acesso para o pesquisador. Estas exigências são importantes porque permitem que o pesquisador faça idas e vindas, quantas vezes quiser, ao campo, de modo a tornar a pesquisa fidedigna, por meio de dados mais próximos da realidade ${ }^{7}$.

Inserido no campo, o pesquisador pode lançar mão de diversos artifícios para a apreensão da realidade estudada. Entretanto, é importante atentar para o fato de que a escolha dos instrumentos também é uma etapa importante da pesquisa. As tecnologias utilizadas para a captação dos dados podem ser dependentes e não-dependentes, tais como o diário de campo, o gravador, a máquina fotográfica e a máquina filmadora. A respeito disso, muitos autores têm opiniões divergentes. 0 diário de campo é um consenso; mas, e os demais instrumentos, devem ser usados? Em que momento utilizálos? No início da pesquisa, quando o pesquisador ainda pode ser visto como um estranho no campo, é aconselhável apenas o uso do diário de campo, no intuito de evitar a intimidação das pessoas ${ }^{7}$. Posteriormente, outras técnicas podem ser utilizadas como complementares. 0 diário sempre deverá estar sendo utilizado; fotografias, filmagens e outras técnicas visuais estão sendo mais utilizadas na pesquisa etnográfica contemporânea, entretanto como recurso complementar, pois a imagem por si não transmite informações, sendo necessário o relatório escrito, por meio dos quais os etnógrafos poderão apresentar de forma minuciosa o contexto estudado e as interações identificadas ${ }^{6,7,10}$; disfarces ou esconderijos do pesquisador para observar sem ser notado nunca devem ser cogitados ${ }^{7}$.

Os valores culturais dos pesquisados devem ser considerados durante todo o processo. Por seu caráter marcante de imersão na realidade exógena, as pesquisas podem subestimar questões sobre ética e respeito cultural no intuito de alcançar os objetivos propostos pelo estudo. Esta atitude descaracteriza um trabalho etnográfico que há muito tempo deixou de tratar os informantes como animais exóticos. Os trabalhos etnográficos devem enxergar os informantes como pessoas que, por possuírem algumas características culturais diferentes, merecem uma investigação. A teoria da enfermagem transcultural baseia-se exatamente neste princípio: da diversidade e universalidade cultural ${ }^{9}$. Somos pesquisadores e pesquisados, todos semelhantes, porém com traços culturais diferenciados.

Perpassando pelas considerações sobre o perfil do pesquisador, as características do campo e a abordagem ética, resta-nos tecer recomendações a respeito do período de inserção no campo e do número de informantes da pesquisa. As recomendações sobre período de tempo de inserção do pesquisador no campo de pesquisa sugerem a permanência de no mínimo seis meses ${ }^{11}$. Entretanto, outros autores reforçam que esse período pode variar de semanas a anos, dependendo, além da natureza do problema, dos objetivos do estudo e da disponibilidade do pesquisador, da aceitação pelo grupo estudado e do número de pessoas envolvidas na coleta de dados $^{6}$. 0 número de informantes também poderá variar dependendo do fenômeno a ser estudado, uma vez que na investigação etnográfica o importante é o significado do depoimento em relação aos objetivos da pesquisa ${ }^{9}$.

Finalmente, para a caracterização de uma pesquisa como etnográfica deve ser observado se o pesquisador fez uso de técnicas tradicionalmente associadas à etnografia (observação participante e entrevista, por exemplo), se o pesquisador foi o instrumento principal na coleta e análise dos dados, se o estudo enfatizou o processo (e não apenas os resultados), se houve preocupação com a descrição da visão dos próprios informantes e se a investigação envolveu um trabalho de campo no ambiente natural dos informantes ${ }^{6}$.

Convém salientar que alguns autores discorrem sobre a tendência para o futuro do etnocentrismo e, conseqüentemente, da pesquisa etnográfica. A diversidade cultural vem rapidamente se suavizando, de modo que as diferenças culturais continuarão a existir, entretanto serão mais sutis. Essa é a atual realidade da etnografia urbana e tende a estender-se para a etnografia realizada em sociedades fechadas. Diante desse fato, os pesquisadores terão que aguçar sua sensibilidade para captar diferenças sutis no contexto que estarão analisando. Conseqüentemente, os textos etnográficos terão que se apresentar mais profundos e menos espetaculares ${ }^{8}$.

ETNOGRAFIA NA ENFERMAGEM: A VALIOSA CONTRIBUIÇÃO DE MADELEINE M. LEININGER

A enfermagem, ciência em constante processo evolutivo, vem há algum tempo reelaborando seu conhecimento no intuito de aprimorar o cuidado e contemplar as mais diversas dimensões do ser humano. Esse processo inclui um novo olhar que busca valorizar aspectos relacionados ao subjetivismo ${ }^{12}$. Aspectos como experiências de vida, valores, crenças, sentimentos, modo de vida e visão de mundo estão sendo considerados extremamente presentes e influentes no sucesso da relação enfermeiro-cliente. 0 cuidado de Enfermagem vem sendo considerado um fenômeno onde o saber popular e 0 saber científico devem convergir a fim de atender às necessidades de saúde e bem-estar do cliente $^{13}$.

Dentro desse contexto, o estudo da cultura constitui um elemento importante, uma vez que possui uma influência marcante sobre o comportamento humano. A etnografia surge como caminho para desvendar culturas, conhecer o outro e, a partir deste conhecimento, reelaborar e direcionar culturalmente as ações de Enfermagem, objetivando formas mais eficientes de desenvolver o cuidado.

0 método etnográfico vem ocupando um espaço importante na Enfermagem contemporânea, principalmente após a elaboração da Teoria do Cuidado Transcultural, que inclui um método de caráter etnográfico, denominado etnoenfermagem.

A teoria supracitada foi desenvolvida pela enfermeira Madeleine M. Leininger, por volta da década de $1940^{9}$. A pesquisadora, ao executar cuidados a pacientes em um hospital geral, reconheceu o valor da investigação a respeito da cultura no cuidado humano ao compreender que seus clientes se comportavam de maneira diferenciada dependendo do contexto cultural no qual estavam inseridos.

Posteriormente, Leininger observou que as culturas determinam práticas de saúde específicas e padrões de cuidado 
prevalentes comuns e que o pensamento e o comportamento em situações de saúde-doença variam entre as diferentes culturas e possuem, também, pontos em comum nas mais diversas culturas.A partir daí, os termos "diversidade" e "universalidade" foram identificados como elementos presentes no contexto cultural e incorporados à teoria.

A teoria foi lançada tendo como base a antropologia e como princípios a influência da visão de mundo, da linguagem, da religião e dos contextos social, político, educacional, econômico, tecnológico, etno-histórico e ambiental sobre 0 comportamento humano.

Na década de 1960, a teoria começou a ser utilizada por enfermeiras pesquisadoras, entretanto de forma muito lenta, pois ela ainda era considerada estranha e diferente. Somente em 1968, quando Leininger lançou o Comitê sobre Enfermagem e Antropologia (CONA), enfermeiras puderam criticar e reestruturar a teoria sob o ponto de vista antropológico. A partir daí, a teoria passou a fazer parte da Enfermagem, principalmente em meados de 1980, por meio de cursos de Enfermagem Transcultural e de outros programas na linha de pesquisa da teoria utilizados em muitas universidades.

0 termo etnoenfermagem foi desenvolvido por Leininger na década de 1980, com o intuito de auxiliar pesquisadores a estudar a teoria. 0 método foi definido como qualitativo e focalizado, sob o ponto de vista naturalístico, nas descobertas, na documentação, na descrição, na explicação e na interpretação da visão de mundo, dos símbolos, dos pensamentos, das experiências de vida dos informantes e de como estes fatores influenciam potencialmente o fenômeno do cuidado de Enfermagem.

0 aprofundamento sobre a Enfermagem Transcultural despertou enfermeiras para a importância da inter-relação entre teoria-pesquisa, de modo que a etnoenfermagem foi sendo desenvolvida com base na teoria do cuidado cultural e utilizada como guia para pesquisas de enfermagem transcultural. A etnoenfermagem passou a ser indicada e considerada relevante para estudos que visam investigar práticas relacionadas ao cuidado, à saúde, ao bem-estar, às experiências nos ciclos de vida, aos modelos preventivos e às outras áreas potenciais envolvendo o fenômeno do cuidado transcultural ${ }^{9}$.

Como suporte para o desenvolvimento da etnoenfermagem, Leininger desenvolveu alguns modelos de pesquisa durante os estudos que realizou em várias culturas diferentes. Ao entrar em contato com os informantes e com seus respectivos contextos culturais, Leininger, a partir da década de 1950, concebeu a idéia de "modelos" para provar, explicar ou descobrir fenômenos complexos e ambíguos, como o cuidado humano.

Tendo como foco a necessidade de uma investigação participativa e cooperativa, congruente com o paradigma qualitativo, a teorista lançou os modelos que a auxiliaram em pesquisas bem-sucedidas. Esses modelos foram aplicados por Leininger durante a realização de investigações de culturas estrangeiras e desenvolvidos por ela a partir de estudos comparativos entre cuidados culturais diferentes. Todavia, o foco dos modelos desenvolvidos por Leininger está na relação pesquisador-informante.

No contexto atual, os modelos de Leininger podem ser utilizados nos mais diversos tipos de sistemas culturais e para investigar problemas relacionados aos cuidados vinculados aos mais diferentes temas particulares de enfermagem nos quais estejam presentes o paradigma qualitativo, o cuidado cultural e a relação direta entre pesquisador e informante. As características culturais de um indivíduo, família, comunidade ou país obedecem ao princípio da diversidade e universalidade do cuidado cultural e possuem, portanto, pontos diferentes e semelhantes às de outras unidades de cuidado. Assim, mesmo quando a investigação não acontece em países estrangeiros, como aconteceu na ocasião do desenvolvimento dos modelos, mas em microculturas ou culturas particulares de um mesmo país, como em uma unidade familiar, os modelos desenvolvidos por Leininger consistem em guias imprescindíveis para auxiliar o pesquisador a se inserir, permanecer, observar e desenvolver a coleta de dados. Dessa forma, os modelos podem ser utilizados em pesquisas sobre o cuidado cultural em relação, por exemplo, à alimentação infantil, prevenção de doenças sexualmente transmissíveis e gravidez precoce, e serem desenvolvidos em cidades, bairros, escolas, famílias ou grupos particulares.

Entre os modelos desenvolvidos por Leininger, destacamse: "Observação-Participação-Reflexão (modelo OPR)", "Estranho-Amigo", "Aculturação" e "Sunrise (Sol Nascente)"14. 0 OPR consiste em um guia composto por quatro fases que auxiliam o pesquisador a se inserir gradativamente e permanecer no contexto natural de seus informantes; o modelo "EstranhoAmigo" possui seis apontamentos sobre a substituição da imagem do pesquisador-estranho pela do pesquisador-amigo que auxiliam na identificação do momento em que os dados obtidos passam a ser autênticos e confiáveis; o modelo de "Aculturação" foi criado por Leininger para avaliar o grau de aculturação de um indivíduo ou grupo inserido em uma subcultura, isto é, para mensurar em que extensão indivíduos ou grupos de uma cultura particular são mais tradicionalmente ou não tradicionalmente orientados e para identificar fatores culturais variáveis e universais entre determinadas culturas; já o modelo "Sunrise" consiste em um guia cognitivo que auxilia na compreensão sobre como os componentes da teoria da diversidade e universalidade do cuidado cultural podem influenciar a saúde da unidade de cuidado ${ }^{9}$. Esses modelos contribuíram para a orientação de pesquisadores na utilização da teoria e, conseqüentemente, promoveram o reconhecimento da importância da teoria para a realização de descobertas na enfermagem.

0 reconhecimento da teoria serviu para ressaltar a influência da cultura sobre o cuidado. Segundo a própria teorista, o cuidado tem sido esquecido na antropologia assim como a cultura tem sido na enfermagem ${ }^{9}$. 0 resgate da relevância da influência cultural sobre o comportamento humano, sobretudo a partir de uma abordagem interdisciplinar, na qual o profissional precisa estar envolvido em um processo de cooperação, respeito à diversidade cultural, abertura para o outro, diálogo e humildade ${ }^{15}$, oferece subsídios para a descoberta de fatores que estejam dificultando ou impedindo o cuidado.

0 cuidado humano satisfatório resulta da interação entre 0 saber popular e o conhecimento acadêmico. 


\section{CONSIDERAÇÕES FINAIS}

A pesquisa etnográfica passou por várias etapas durante sua evolução. Inicialmente foi utilizada por viajantes de forma agressiva, com os chamados nativos das tribos indígenas. Gradativamente foi se descobrindo que aqueles pertencentes a outras culturas não eram animais exóticos, mas seres humanos com características culturais semelhantes e diferentes de nossa cultura. 0 estopim da evolução da etnografia ocorreu quando a cidade foi descoberta como laboratório natural. Desde então a etnografia se tornou um método passível de ser realizado em diversos ambientes.

A utilização do método etnográfico na enfermagem ganhou ênfase com a elaboração da Teoria do Cuidado Transcultural. A teoria de Madeleine Leininger ressalta a forte influência dos fatores culturais sobre o comportamento e, conseqüentemente, sobre o cuidado de enfermagem. Por meio da definição da diversidade e universalidade cultural e do suporte metodológico

\section{Referências}

1. Haguette TMF. Metodologias qualitativas na sociologia. Petrópolis (RJ): Vozes; 1992.

2. Geertz C. A interpretação das culturas. Rio de Janeiro (RJ): LTC; 1989.

3. Lüdke M, André MEDA. Pesquisa em educação: abordagens qualitativas. São Paulo: EPU; 1986.

4. Laraia RB. Cultura: um conceito antropológico. Rio de Janeiro(RJ): J. Zahar; 2006.

5. Tronchin DMR, Tsunechiro MA. A experiência de tornarem-se pais de prematuro: um enfoque etnográfico. Rev Bras Enferm 2005; 58(1): 49-54.

6. André MEDA. Etnografia da prática escolar. Campinas (SP): Papirus; 1995.

7. Winkin Y. A nova comunicação: da teoria ao trabalho de campo. Campinas (SP): Papirus; 1998.

8. Geertz C. Nova luz sobre a antropologia. Rio de Janeiro (RJ): J. Zahar; 2001. acoplado à teoria, denominado etnoenfermagem, enfermeiros passaram a valorizar o conhecimento da cultura como algo essencial para um cuidado eficaz. Entretanto, apesar de a pesquisa etnográfica estar se tornando cada vez mais próxima da realidade da pesquisa em enfermagem, ainda existe um desconhecimento acerca do método, ainda compreendido como restrito a uma minoria de intelectuais com anos de formação ou mesmo considerado um método a ser realizado apenas em sociedades fechadas ou com classes menos privilegiadas.

Através da realização deste estudo, pudemos ampliar nossas visões a respeito da pesquisa etnográfica, sobretudo no contexto da Enfermagem. Esperamos que a pesquisa contribua para a divulgação do método e incentive sua utilização de forma apropriada, pois acreditamos que cultura, enfermagem e cuidado estabelecem uma estreita relação. A análise desta relação em diversas situações do cotidiano do enfermeiro é importante não só para o aprimoramento da prática do cuidado, como também para o crescimento da Enfermagem como disciplina científica.

9. Leininger MM. Transcultural nursing: concepts, theories, research e practice. New York (USA): Mc Graw-Hill; 2002.

10. Melleiro MM, Gualda DMR. Explorando a fotovoz em um estudo etnográfico: uma estratégia de coleta de dados. Rev Bras Enferm 2005; 58(2): 191-93.

11. Ross DD, Kyle DW. Qualitative inquiry: a review and analysis. Trabalho apresentado no Encontro Anual da AERA. New York (USA); 1982.

12. Mathias JJS, Zagonel IPS, Lacerda MR. Processo clinical caritas: novos rumos para o cuidado de enfermagem transpessoal. Acta Paul Enferm 2006; 19 (3): 332-37.

13. Costa LB, Barroso MGT. Convergência de saberes e conhecimentos de enfermagem no cuidador à família. Esc Anna Nery Rev Enferm 2006; 10 (1): $330-32$.

14. Leininger MM. Culture care diversity and universality: a theoria of nursing. New York(USA): National League for Nursing Press; 1991.

15. Gattás MLB, Furegato ARF. Interdisciplinaridade: uma contextualização. Acta Paul Enferm. 2006; 19 (3): 323-27. 